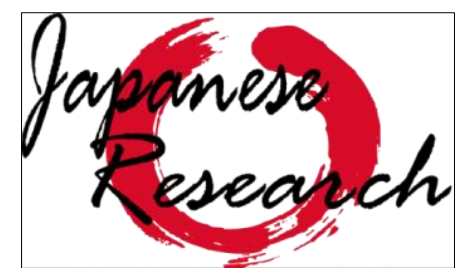

on Linguistics, Literature and Culture
Japanese Research on Linguistics, Literature, and Culture Vol. 2 No. 1 Nov. 2019, p., 93-107 ISSN Online: 2655-4836

DOI: $10.33633 /$ jr.vlil.3445

http://publikasi.dinus.ac.id/index.php/jrllc/article/view/3445/1856

japanese.research@fib.dinus.ac.id

Published by Universitas Dian Nuswantoro, Semarang

\title{
Prinsip Buddha Zen dalam Upacara Chanoyu Aliran Urasenke
}

\author{
Widya Magdalena \\ Universitas Dian Nuswantoro \\ 312201100340@mhs.dinus.ac.id
}

Article History: Submitted date 2019-10-28; Accepted date 2019-11-9; Published date 2019-11-30

\begin{abstract}
This research discusses about the application of the Zen Buddhism principles in urasenke style tea ceremony. The purpose of this research is to explain the application of the Zen principles (wa, kei, sei, jaku) in urasenke style tea ceremony. This research used descriptive qualitative method to analyze the data. This study uses the principles given by Sen no Rikyu. These principles are wa (harmony), kei (respect), sei (purity), and jaku (tranquility). The results of this study show that the four principles are applied through the actions taken by the host and guest in the urasenke style tea ceremony.
\end{abstract}

Keywords : chanoyu, urasenke, buddhism, zen, Japan

\begin{abstract}
Abstrak
Penelitian ini membahas penerapan prinsip Buddha Zen dalam upacara chanoyu aliran urasenke. Tujuan penelitian adalah menjelaskan penerapan dari prinsip Zen (wa, kei, sei, jaku) dalam upacara chanoyu aliran urasenke. Dalam penelitian ini menggunakan metode deskriptif kualitatif untuk memahami data. Penilitian menggunakan prinsip yang diberikan oleh Sen no Rikyu. Prinsip ini adalah wa (harmoni), kei (rasa hormat), sei (kemurnian), jaku (ketenangan). Hasil dari penelitian ini adalah keempat prinsip ini diterapkan melalui tindakan yang dilakukan oleh tuan rumah dan tamu dalam upacara chanoyu aliran urasenke.
\end{abstract}

Kata kunci : chanoyu, urasenke, buddha, zen, Jepang

\section{Pendahuluan}

Jepang merupakan sebuah negara yang memiliki banyak kebudayaan. Kebudayaan Jepang banyak dipengaruhi oleh kebudayaan Cina. Hal ini terbukti dari tulisan Jepang (kanji) sama seperti dengan tulisan Cina (hànzì). Selain itu, pada awal pertengahan abad ke-6 banyak pelajar dari Jepang yang datan ke Cina untuk belajar di sana kemudian kembali ke Jepang dan menerapkan apa yang mereka pelajari selama mereka di Cina. Pada abad ini pula sebuah kepercayaan baru masuk ke Jepang. Kepercayaan itu adalah 
Buddhisme Cina. Buddhisme Cina mencapai puncak kejayaannya pada abad ke-8 dan abad ke-12. Pada abad ke-12 dan abad ke-13, Zen masuk ke Jepang.

Buddha Zen dibawa masuk ke Jepang oleh Dogen dan Eisai. Dogen adalah salah satu pendiri aliran Zen di Jepang yang bernama soto. Soto menekankan meditasi shikantaza sebagai cara menghapus kesadaran dari pikiran dan tubuh, dengan pencerahan disebut keadaan murni. Sementara Eisai mendirikan aliran Rinzai, yang menekankan pada kensho ("melihat asal usul diri", atau pencerahan). Zen ini diterapkan pada karya seni berupa lukisan (sumi-e dan ensho) dan puisi (haiku). Selain karya seni, Zen juga diterapkan pada 茶の湯 (chanoyu atau upacara minum teh). 茶の湯 (chanoyu) atau sering disebut dengan 茶道 (chadō) adalah ritual tradisional Jepang dalam menyajikan teh untuk para tamu. Chanoyu berasal dari kata cha (茶) yang berarti the dan yu (湯 ) yang berarti air panas, jadi chanoyu adalah teh dengan air panas. Dalam ritual ini bukan sekedar menyajikan dan meminum teh panas saja tetapi ada beberapa proses yang harus dilakukan dalam ritual ini. Upacara minum teh ini memiliki konsep 一期一会(Ichi-go ichi-e) yang berarti satu waktu, satu pertemuan.

Teh sudah masuk pada jaman Heian (794-1185), teh yang masuk pada saat ini adalah teh coklat dan berfungsi sebagai obat. Teh pada masa ini sangat sedikit jumlahnya. Pada jaman Kamakura (1185-1333), teh hijau mulai masuk bersamaan dengan Buddha, yang dibawa oleh Eisai. Seiring dengan penyebaran agama Buddha di Jepang, teh semakin terkenal di Jepang. pada abad ke-16, Sen no Rikyu memperkenalkan upacara minum teh secara luas. Sen no Rikyu mengikuti gurunya, Takeno Jōō, menerapkan konsep ichi-go-ichie. Dia juga mengembangkan secara luas upacara minum teh dengan prinsip-prinsip baru. Prinsip tersebut adalah 和 (wa atau harmoni), 敬 ( kei atau rasa hormat), 清 (sei atau kemurnian, kebersihan), 寂(jaku atau ketenangan).

Setelah Sen no Rikyu meninggal, anak dari Sotan, cucu Sen no Rikyu, membagi properti untuk anak-anaknya. Bagian depan rumah utama diberikan kepada Koshin Sosa. Senso Soshitsu mewarisi bagian belakang rumah. Sebuah rumah di jalan Mushakoji diberikan kepada Ichio Soshu. Dari teh sini muncullah aliran sanseke (tiga keluarga Sen) yaitu, Urasenke, Omotesenke, dan Mushakojisenke. Urasenke merupakan salah satu dari tiga aliran chanoyu. Aliran ini adalah aliran terbesar diantara aliran yang lainnya. Urasenke 
memiliki ruangan minum teh yang bernama Konnichian. Konnichian dibangun oleh Sen Sotan. Ruangan minum teh ini adalah replika dari empat setengah tatami ruangan minum teh Sen no Rikyu dan delapan tatami kanuntei. Ruangan ini juga melambangkan semangat wabi dari Sotan. Dalam tata cara upacara chanoyu ketiga aliran ini memiliki cara yang sama dalam melaksanakan upacara chanoyu. Hanya saja, ada sedikit perbedaan dalam upacara tersebut. Misalnya seperti: teh yang dihasilkan, peralatan yang digunakan, dan tata cara lainnya.

\subsection{Metode Penelitian}

Penelitian ini menggunakan metode deskriptif yakni dengan cara memerikan penerapan keempat prinsip Buddha Zen dalam upacara chanoyu aliran urasenke. Data yang digunakan adalah sebuah video upacara chanoyu aliran urasenke yang dipratikkan oleh salah satu kelas di Hakone Foundation di Amerika Serikat yang berjudul "Present! - Tea Ceremony- Urasenke Style".

Teknik pengumpulan data yang penulis lakukan untuk meneliti video upacara chanoyu aliran urasenke, adalah mencari dan mendownload video tersebut dari internet, lalu menonton sumber data, yaitu video Present! - Tea Ceremony- Urasenke Style, kemudian membuat skrip video tersebut dan mencari kanji yang tepat untuk tiap kata dalam kalimatnya dengan melibatkan native speaker, kemudian menerjemahkan ke dalam bahasa Indonesia, berikutnya meliteralisasi cara baca huruf Jepang ke dalam huruf alfabet, dan yang terakhir mengelompokan data berdasarkan sub bab, yaitu 1) 敬(kei) 2) 和(wa) 3) 清(sei) 4)寂(jaku).

Teknik-teknik dalam menganalisis data adalah dengan cara diurutkan berdasarkan jumlah data terbanyak. Penulis menampilkan data yang dianalisis. Data tersebut berupa gambar atau dialog yang menunjukan penerapan prinsip Zen. Mendiskripsikan data sesuai dengan gambar atau dialog. Interprestasi data tentang penerapan dan makna dalam data tersebut. Menarik kesimpulan berdasarkan data yang dianalisis.

\section{Hasil dan Pembahasan}

Pembahasan data-data yang menunjukkan penerapan prinsip Zen dalam upacara chanoyu aliran urasenke yang telah penulis kelompokkan. Berikut data yang menunjukan penerapan Zen dalam upacara chanoyu aliran urasenke;

\section{1) 敬 (Kei atau rasa hormat)}




\section{Gambar 1}

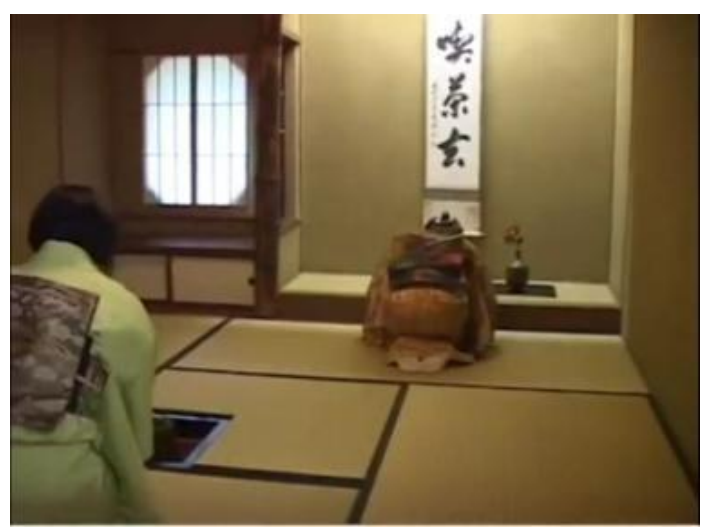

Gambar 1 adalah gambar ketika ketika tamu memasuki ruangan minum teh (chashitsu). Para tamu akan menunduk sebanyak dua kali untuk menghomati chabana (karangan bunga) dan kakejiku (gulungan yang digantung yang berisi kaligrafi atau gambar). Rasa hormat tamu kepada chabana dan kakejiku. Dalam buku The Art of Chabana: Flowers for the Tea Ceremony Sen no Rikyu mengatakan bahwa mengatakan bahwa bunga (chabana) harus sama seperti ketika mereka berada di tanah. (Mittwer, 1992:39). Chabana merupakan lambang dari alam. Ketika tuan rumah menghormati chabana pertama kalinya, ini membuktikan bahwa alam adalah hal yang penting, karena kita berasal dari alam tanpa alam kita tidak akan ada dan tanpa alam tidak ada yang namanya kehidupan.

Kakejiku merupakan sebuah gulungan yang ditulis oleh pendeta Buddha yang ditujukan kepada semua orang yang berada dalam ruangan minum teh karena mereka menunjukkan rasa hormat meminum teh dihadirat orang suci. (Sadler, 2011:62). Tulisan yang ditulis oleh para biksu di dalam kakejiku (gulungan yang digantung yang berisi kaligrafi atau gambar) ditujukan kepada Buddha. Ketika Ketika para tamu menundukan dirinya untuk kakejiku (gulungan yang digantung yang berisi kaligrafi atau gambar), sama saja dengan para tamu menghormati Buddha.

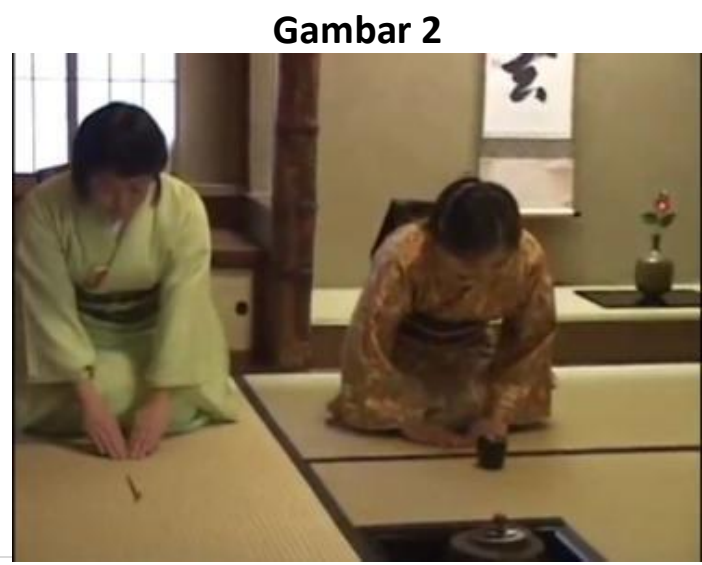


Pada gambar 2 adalah ketika ketika tuan rumah mengizinkan para tamu untuk melihat natsume (tempat bubuk teh) dan chasaku (sendok bubuk teh). Rasa hormat kepada kedua peralatan ini ditunjukkan ketika para tamu akan melihat natsume (tempat bubuk teh) dan chasaku (sendok bubuk teh), mereka menundukan diri terlebih dahulu. Ketika para tamu menghormati natsume dan chasaku, hal ini berarti bahwa para tamu menghormati teh yang merupakan bagian paling penting dalam upacara ini. Selain itu, tanpa peralatan tersebut upacara chanoyu tidak dapat terlaksana dengan baik.

\section{Gambar 3}

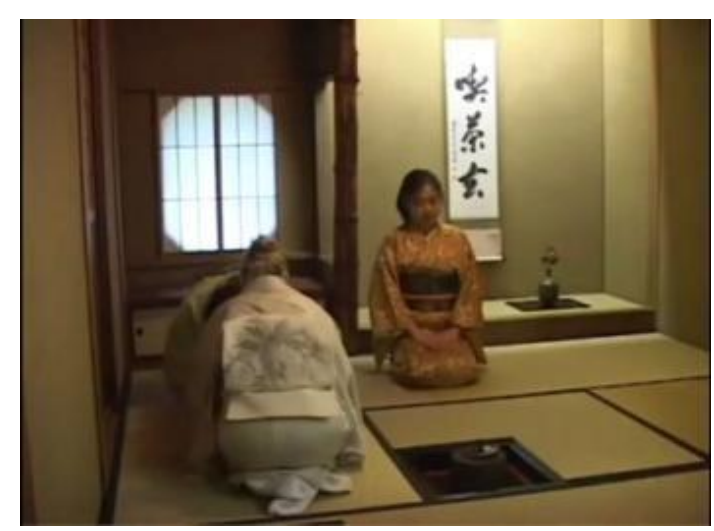

Pada gambar 3 adalah ketika tuan rumah akan masuk lalu membawa manisan (okashi) untuk para tamu. Penghormatan tuan rumah ke tamu dengan cara menundukan dirinya di depan tamu. Begitu pula dengan tamu, rasa hormatnya ditunjukan ketika dia menundukan dirinya di depan tuan rumah. Rasa hormat sangat penting ketika kita berjumpa dengan orang lain. Ketika kita bisa menghomati orang lain walaupun kita baru pertama kali bertemu, kita bisa membuka sebuah pintu kekeluargaan.

Penghormatan tuan rumah kepada tamu terlihat dari cara tuan rumah membuatkan teh untuk tamu pertama. Ketika tuan rumah menyajikan teh untuk tamu, harus menyajikan teh yang terbaik. Tuan rumah memperlakukan para tamu seperti dirinya sendiri sehingga dia memberikan para tamu teh yang terbaik. Rasa hormat tamu terhadap tuan rumah ditunjukan ketika tamu menghabiskan teh. Ketika tamu menghabiskan teh yang dibuat oleh tuan rumah, itu menandakan bahwa teh yang dibuat oleh tuan rumah enak juga sebagai tanda penghormatan karena sudah mengundang tamu dalam upacara chanoyu yang sakral ini. 


\section{Gambar 4}

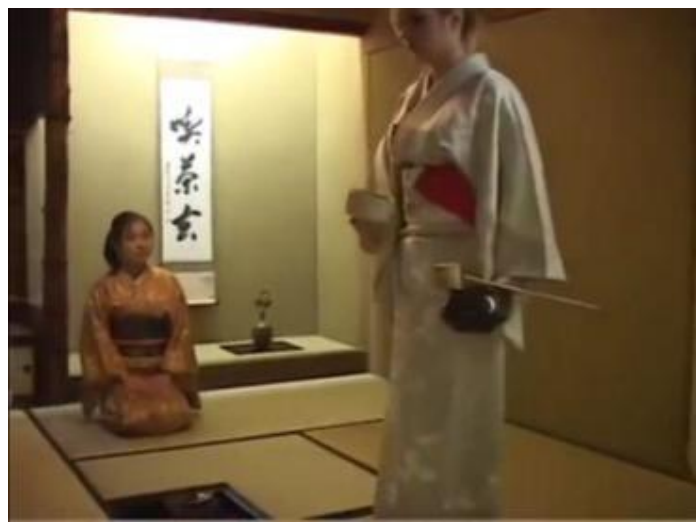

Pada gambar 4 adalah adegan ketika tuan rumah membawa masuk peralatan upacara minum teh. Rasa hormat ditunjukan dari cara tuan rumah membawa chawan (mangkuk minum teh), chawan (mangkuk minum teh) dibawa masuk bersamaan dengan natsume dan chasaku yang merupakan peralatan utama dalam upacara chanoyu ini. Setelah itu dia membawa chawan milik tamu yang lain, lalu peralatan chanoyu lainnya. Ketika chawan (mangkuk minum teh) dibawa masuk ke ruangan setelah peralatan yang bersentuhan dengan bubuk teh secara langsung. Hal ini membuktikan bahwa kehadiran tamu sangat penting, setelah teh itu sendiri, dalam upacara chanoyu ini, tanpa para tamu upacara chanoyu tidak dapat terlaksana.

\section{2) 和 ( $W a$ atau harmoni)}

Gambar 5

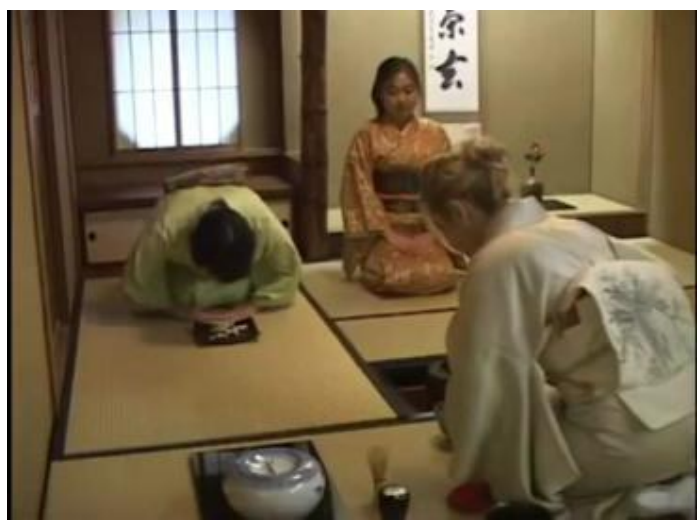

Pada gambar 5 adalah ketika ketika tuan rumah akan memulai pembuatan teh, dia akan menunduk sambil berkata, “お菓子はどうぞ。”“Okashi wa douzo.” yang berarti, "Silahkan memakan manisannya." Tamu membalasnya dengan menunduk lalu memakan manisan (okashi) tesebut.

Harmoni yang terjadi dalam adegan tersebut adalah sebuah interaksi antara tuan rumah dengan tamu. Interaksi itu berupa sebuah percakapan singkat yang mengijinkan 
tamu memakan manisan (okashi). Percakapan ini menunjukkan bahwa tuan rumah akan segera memulai membuat teh, jika tuan rumah tidak berbicara seperti ini maka ketika teh sudah jadi sementara tamu baru memulai memakan manisan (okashi) maka teh yang seharusnya nikmat, kenikmatannya bisa berkurang hanya karena tuan rumah tidak memberi tahu kapan harus memakan manisan (okashi). Selain itu, jika tamu mengambil manisan (okashi) sebelum diijinkan oleh tuan rumah, hal itu merupakan hal yang tidak sopan. Jika tamu tidak sopan maka tuan rumah tidak akan mau menjalin hubungan dengan tamu.

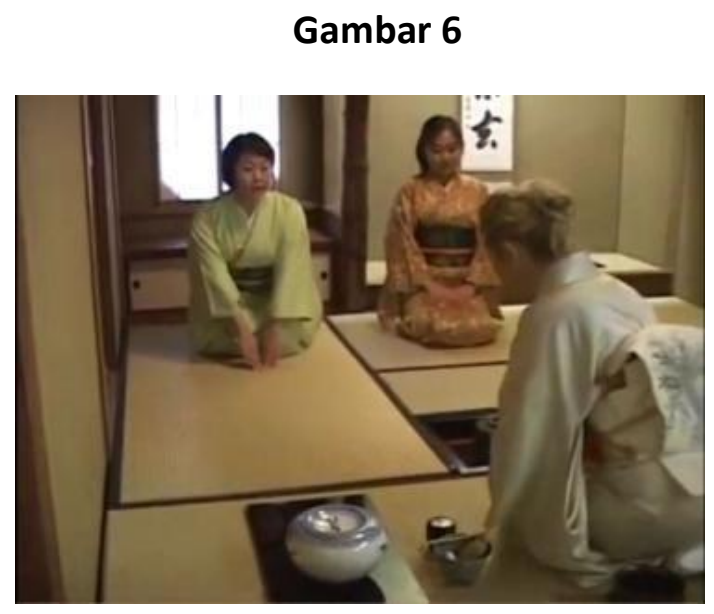

Gambar 6 adalah gambar ketika tuan rumah mempersilakan para tamu melihat dan memegang natsume dan chasaku secara langsung. Tuan rumah akan berkata, “お霜やお茶 策の帱見おねがいいたします。”“O natsume ya o chasaku no haiken onegai itashimasu” yang berarti, "Silahkan melihat natsume dan chasaku." yang kemudian dijawab oleh tamu pertama dengan memberi hormat

Harmoni di atas terlihat dari interaksi antara tuan rumah dengan tamu, ketika tuan rumah mengijinkan para tamu untuk melihat peralatan dari chanoyu. Ketika tuan rumah mengijinkan para tamu melihat dan memegang kedua peralatan tersebut membuktikan bahwa tuan rumah sudah menganggap para tamu seperti keluarga sendiri. Sehingga tidak ada yang disembunyikan dari para tamu, bahkan hal terpenting dalam upacara tersebut diperlihatkan secara langsung. 


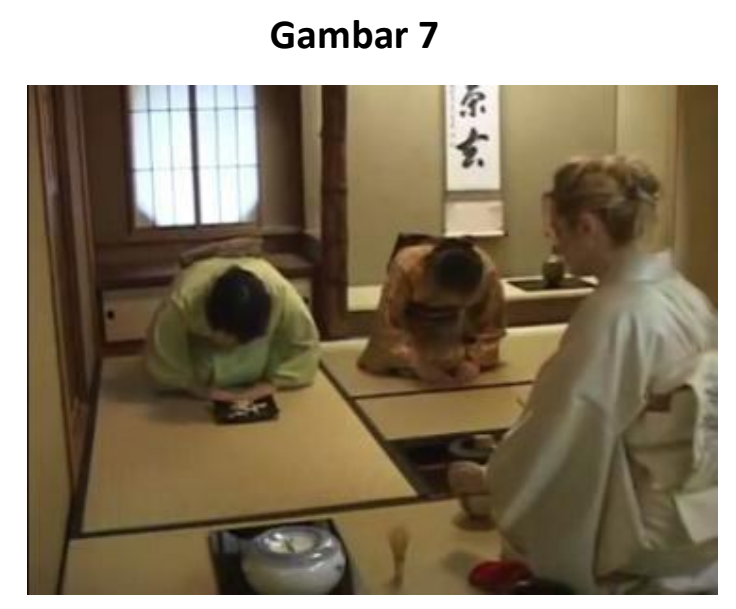

Pada gambar 7 adalah ketika ketika tamu pertama akan memakan manisan (okashi) yang diberikan oleh tuan rumah dan. Dia akan berkata, “お先に失礼します。”“O saki ni shitsureshimasu" yang berarti, "Maaf, saya duluan." Kemudian dijawab oleh sebuah bungkukan oleh tamu kedua.

Adegan tersebut merupakan sebuah interaksi antara tamu pertama dan tamu kedua. Tamu pertama meminta izin dari tamu kedua untuk meminum teh. Tamu kedua menjawabnya dengan sebuah bungkukan badan yang menandakan bahwa tamu kedua mempersilahkan tamu pertama untuk memakan manisan dan meminum teh. Begitu pula ketika tamu kedua ketika akan memakan manisan dan meminum teh, dia akan berkata hal yang sama seperti tamu pertama. Sebuah interaksi dalam upacara chanoyu bukan hanya antara tamu pertama dengan tuan rumah, tetapi dengan tamu kedua. Semua orang yang ada di dalam ruangan tersebut harus saling berinteraksi, supaya dapat terjalinnya sebuah hubungan yang baik. Ada sebuah interaksi lagi yaitu antara tuan rumah dengan peralatan chanoyu. Interaksi ini terlihat di sepanjang upacara chanoyu, ketika tuan rumah membawa masuk dan keluar peralatan dia membawa dengan penuh hati-hati, tidak ada perlakuan khusus, semua diperlakukan sama. Tuan rumah juga menggunakan peralatan sesuai dengan fungsinya masing-masing. Tuan rumah tidak menggunakan chasaku (sendok bubuk teh) untuk mengocok bubuk teh dengan air panas, atau membuang sisa air yang digunakan untuk membersihkan chawan (mangkuk minum teh) ke dalam kama (tempat memanaskan air). Ketika tuan rumah menggunakan peralatan sesuai dengan fungsinya masing-masing, tuan rumah menganggap bahwa peralatan itu sama seperti dirinya sendiri. Dia tidak mau menyalah gunakan peralatan tersebut. Peralatan itu sangat penting, walaupun tuan rumah sudah ahli dalam upacara chanoyu tapi tanpa peralatan chanoyu dia tetap tidak bisa 100 | P a g e 
melakukan upacara chanoyu. Dari sini dapat terlihat rasa menghargai tuan rumah terhadap peralatan chanoyu.

Selain itu, harmoni juga terlihat dari pemilihan tuan rumah terhadap chabana (karangan bunga), kakejiku ((gulungan yang digantung yang berisi kaligrafi atau gambar), dan peralatan minum teh. Harmoni ditunjukan ketika tuan rumah memilih chabana (karangan bunga), kakejiku (gulungan yang digantung yang berisi kaligrafi atau gambar), dan peralatan minum teh memiliki keserasian dengan tema dan musim pada saat upacara chanoyu dilaksanakan.

\section{3) 清(sei atau kemurnian)}

\section{Gambar 8}

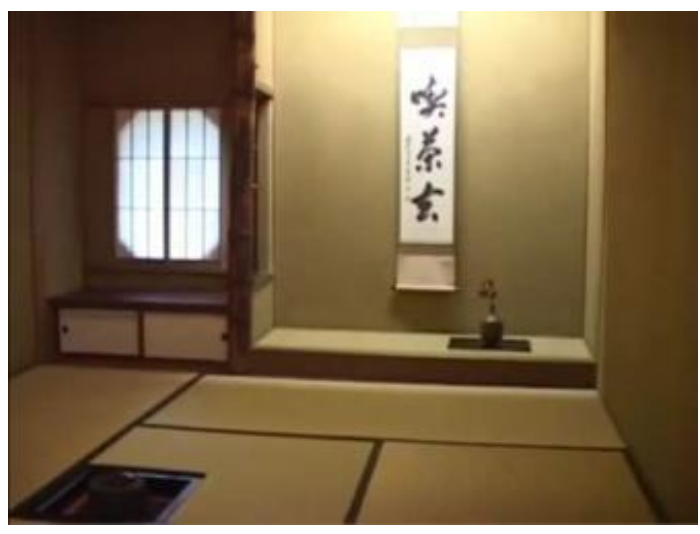

Gambar 8 adalah gambar dari ruangan minum teh (chashitsu). Kemurnian (sei) terlihat dari ruangan yang digunakan dalam upacara chanoyu (chashitsu) terlihat bersih pada saat upacara belum dimulai maupun ketika sudah dimulai. Sesuatu yang murni adalah sesuatu yang tidak memiliki noda atau kotor, dengan kata lain sesuatu yang murni itu bersih. Zen percaya pada kemurnian batin dan kebaikan (Suzuki, 1964:40). Dengan membuat ruangan minum teh (chashitsu) bersih maka hal itu membuat orang yang berada dalam ruangan itu memiliki batin yang murni juga, karena keadaan di sekitar kita sangat mempengaruhi suasana batin kita. 


\section{Gambar 9}

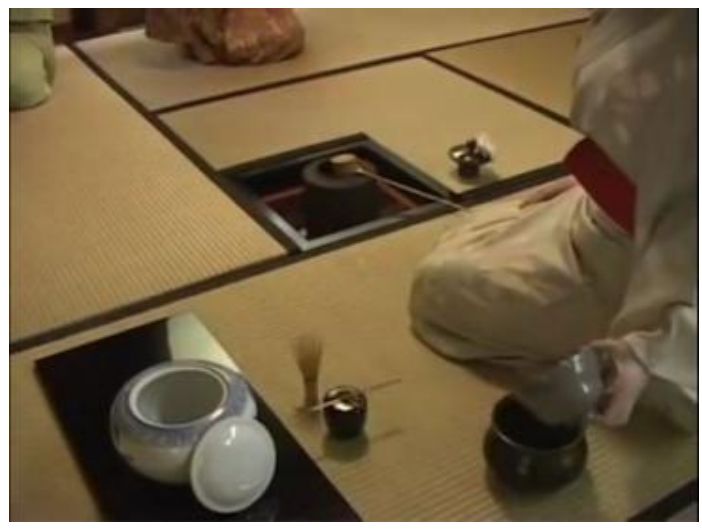

Pada gambar 9 adalah gambar ketika tuan rumah membersihkan peralatan chanoyu. Kemurnian diterapkan ketika akan memulai membuat teh, tuan rumah akan membersihkan peralatannya terlebih dahulu. Ketika tuan rumah menyajikan teh dengan peralatan yang bersih, tuan rumah berharap ketika tamu meminum teh dari peralatan yang sudah dibersihkan, tamu bisa memiliki sebuah hati yang murni. Karena hati yang murni adalah Buddha (Suzuki, 1973:305).

But the art of tea is here more concerned with general cleansing and orderliness, which tend to make the mind free from unnecessary psychological encumbrance.

'Tetapi seni teh lebih cenderung kepada keberisihan secara umum dan ketertiban, yang membuat pikiran bebas dari beban psikologis.'

Kutipan di atas dikatakan oleh Suzuki (1973:305). Dari kutipan di atas dapat disimpulkan bahwa ketika tuan rumah membuat peralatan minum teh menjadi bersih terlebih dahulu setelah itu diberikan kepada tamu, dan ketika tamu meminum teh dari peralatan yang bersih maka pikiran dan batin tamu bisa bebas dari segala masalah.

Gambar 10

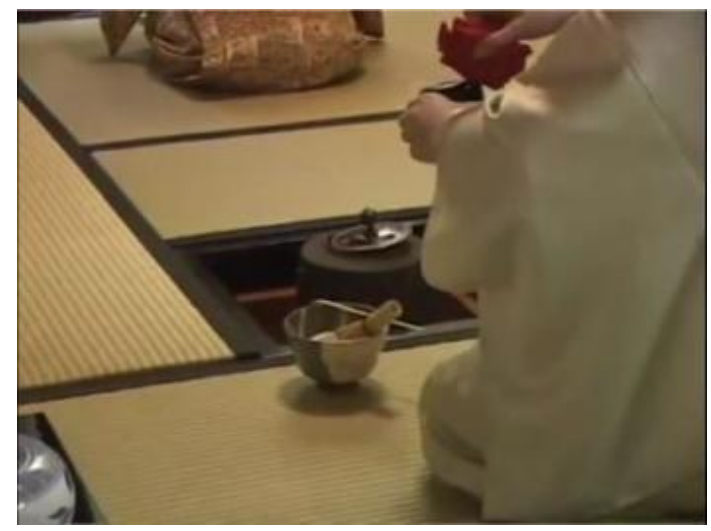


Pada gambar 10 adalah gambar adegan setelah upacara chanoyu selesai, Tuan rumah akan membersihkan peralatan chanoyu. Ini dimaksudkan agar peralatan chanoyu tetap murni. Ketika tuan rumah menganggap peralatan seperti dirinya sendiri, maka pada bagian ini adalah bagian yang sangat penting. Jika di awal peralatan dibersihkan untuk memurnikan para tamu, di bagian akhir ini peralatan dibersihkan untuk memurnikan peralatan itu sendiri. Ketika peralatan tetap murni, maka kemurnian dari upacara chanoyu dapat terjaga karena peralatan chanoyu juga merupakan bagian yang terpenting dalam upacara chanoyu.

\section{Gambar 11}

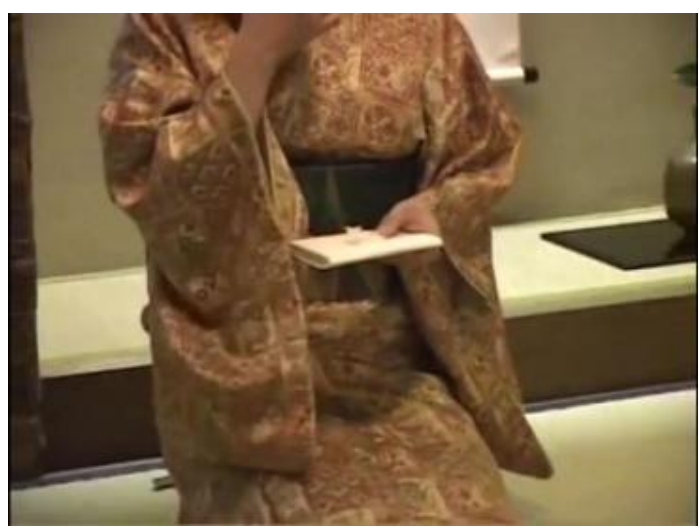

Pada gambar 11 terjadi ketika tamu memakan manisan yang disediakan oleh tuan rumah di awal. Proses pemurnian yang dilakukan oleh tamu adalah ketika tamu tidak membuang bungkus dari manisan (okashi) ke chashitsu (ruangan minum teh). Ini menunjukan bahwa tamu juga menjaga kemurnian di ruangan tersebut. Ketika tamu menjaga kemurnian tersebut, tamu juga menjaga batin dari orang yang sekarang atau nantinya berada dalam ruangan tersebut. Di dalam ruangan tersebut, ada chabana (karangan bunga) dan kakejiku (gulungan yang digantung yang berisi kaligrafi atau gambar) yang merupakan lambang dari alam dan Buddha, jika ruangan tersebut kotor, sama saja menghina keberadaan mereka.

\section{4) 寂 (jaku atau ketenangan)}

Konsep jaku atau ketenangan terlihat pada sepanjang upacara chanoyu. Ketika tuan rumah maupun para tamu mampu menerapkan konsep wa (harmoni), kei (rasa hormat), sei (kemurnian) maka ketenanganlah yang muncul. Jaku merupakan titik tertinggi 
dalam upacara chanoyu. Upacara chanoyu bukan hanya berbicara tentang kenikmatan teh, tetapi juga hal lain seperti yang dikatakan oleh Suzuki (1973 : 306).

But, in reality, the principle of tranquillity is something that emanates from one's inner consciousness as it especially understood in the art of tea.

'Tetapi, dalam kenyataannya, prinsip dari ketenangan adalah sesuatu yang berasal dari kesadaran batin seseorang terutama yang dipahami dalam seni teh.'

Dalam kutipan di atas membuktikan bahwa upacara chanoyu juga berbicara dalam ketenangan dari batin orang yang berada di dalam ruangan tersebut. Ketika berada dalam ruangan tersebut, orang dan chashitsu menjadi satu (Suzuki, 1973:306). Ketika mereka menjadi satu, mereka dapat merasakan segala sesuatu yang murni dan bebas dari segala hal duniawi. Kemurnian adalah milik subyek dan obyek, tetapi ketenangan adalah kualitas dari spiritual. (Suzuki, 1973:306)

Ketenangan akan bertambah ketika ada orang lain beserta peralatan lain di dalam ruangan tersebut sambil memikirkan hal-hal spiritual secara bersama-sama. Dengan kehadiran orang lain dan peralatan sama sekali tidak mengganggu ketenangan karena ketika mereka menyatu dengan chashitsu (ruangan minum teh) sama seperti kita maka kita adalah satu. Setiap orang dan benda yang ada di dalam ruangan tersebut memiliki elemen ketenangan, jika dijadikan satu maka ketenangan akan semakin bertambah.

\section{Gambar 12}

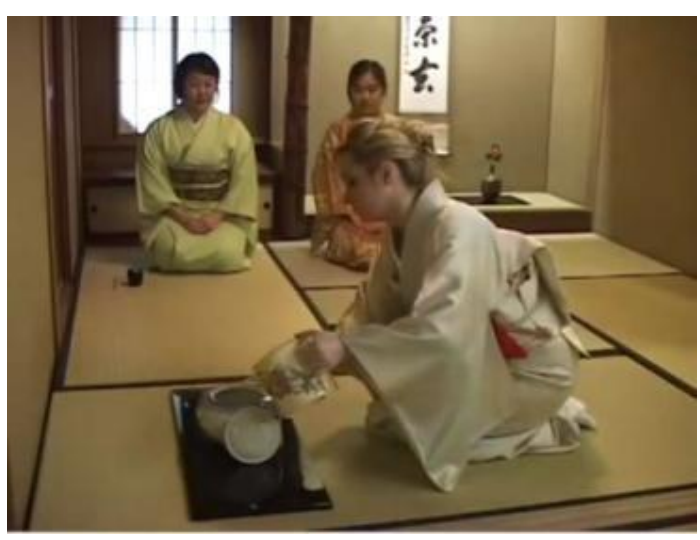

Pada gambar 12 adalah penerapan jaku secara tindakan. Gambar di atas adalah adegan yang terjadi ketika tuan rumah mengambil air dari mizusashi (tempat air dingin) kemudian dimasukan ke dalam kama (tempat memanaskan air) sebanyak air yang sudah digunakan. Kemudian air yang dingin yang berasal dari mizusashi (tempat air dingin) 
dicampur dengan air panas di dalam kama (tempat memanaskan air). Tuan rumah juga mengisi kembali mizusashi (tempat air dingin) kembali.

Hal tesebut penting dilakukan karena ketika akan menadakan chanoyu berikutnya tidak terjadi kepanikan karena kehabisan air di dalam kama (tempat memanaskan air) maupun mizusashi (tempat air dingin). Jika terjadi kepanikan maka jaku tidak bisa diterapkan dalam upacara berikutnya. Ketika jaku hilang maka tuan rumah maupun tamu hanya mendapat kenikmatan teh saja dalam upacara chanoyu, mereka tidak akan mendapat kenikmatan secara spiritual yang merupakan hal yang paling penting dalam upacara chanoyu

\section{Simpulan}

茶の湯(chanoyu) atau sering disebut dengan 茶道 (chadō) adalah ritual tradisional Jepang dalam menyajikan teh untuk para tamu. Chanoyu berasal dari kata cha (茶) yang berarti teh dan yu (湯) yang berarti air panas, jadi chanoyu adalah teh dengan air panas. Chanoyu bukan hanya sekedar memberikan teh kepada para tamu, tetapi memiliki proses yang harus dilakukan dengan sungguh-sungguh. Proses ini membutuhkan waktu bertahuntahun untuk bisa melakukan upacara chanoyu secara sempurna.

Teh hijau mulai masuk Pada jaman Kamakura (1185-1333) bersamaan dengan Buddha, yang dibawa oleh Eisai. Seiring dengan penyebaran agama Buddha di Jepang, teh semakin terkenal di Jepang. Kemudian pada abad ke-16, Sen no Rikyu memperkenalkan upacara minum teh secara luas. Dia juga mengembangkan secara luas upacara minum teh dengan prinsip-prinsip baru. Prinsip tersebut adalah 和 (wa atau harmoni), 敬( kei atau rasa hormat), 清 (sei atau kemurnian, kebersihan), 寂 (jaku atau ketenangan).

Prrinsip 和 (wa) yang berarti harmoni. Sebuah harmoni antara tuan rumah dengan tamu dalam sebuah interaksi di dalam upacara chanoyu. Bukan hanya antara tuan rumah dengan tamu saja tetapi dengan alam dan barang-barang yang bisa disentuh. Prinsip ini terlihat pada saat tuan rumah dan tamu berinteraksi. Interaksi ini terjadi pada saat tuan rumah mempersilahkan tamu untuk memakan manisan (okashi), saat tuan rumah akan memulai dan mengakhiri pembuatan teh, saat tamu akan memakan manisan, dan saat tuan rumah memperbolehkan tamu untuk melihat natsume dan chasaku. Selain interaksi tamu dengan tuan rumah, ada pula interaksi antara tamu dengan tamu. Interaksi ini terjadi ketika tamu akan memulai meminum teh. Ada pula interaksi antara tuan rumah dengan 
peralatan. Interaksi ini terjadi ketika tuan rumah menggunakan peralatan sesuai dengan fungsinya.

Prinsip 敬 (kei) yaitu rasa hormat. Rasa hormat kepada semua orang yan berada dalam chashitsu, juga rasa hormat kepada peralatan upacara chanoyu. Prinsip ini terlihat ketika tamu menundukan dirinya kepada chabana yang merupakan lambang dari alam, kakejiku yang merupakan lambang dari Buddha dan natsume serta chasaku yang merupakan lambang dari peralatan chanoyu. Rasa hormat juga ditunjukkan ketika tuan rumah memberikan manisan (okashi) kepada tamu, lalu cara tuan rumah membawa masuk peralatan upacara chanoyu, juga cara tuan rumah membuat teh, dan ketika tamu meminum teh.

Prinsip 清 (sei) yaitu kemurnian. Kemurnian dilakukan melalui tindakan pembersihan. Kemurnian bukan hanya berbicara tentang kebersihan tetapi hati yang murni. Prinsip ini terlihat dari cara tuan rumah menjaga kebersihan peralatan dan juga chashitsu. Bukan hanya tuan rumah, tetapi para tamu juga menjaga kebersihan chashitsu.

Prinsip 寂 (jaku) yaitu ketenangan. Ketenangan merupakan tujuan akhir sekaligus awal. Ketika tuan rumah maupun para tamu mampu menerapkan konsep wa, kei, dan jaku maka ketenanganlah yang muncul. Jaku diterapkan ketika tuan rumah mengisi kembali air yang sudah digunakan dalam upacara chanoyu. Tanpa tindakan ini jaku tidak bisa diterapkan dalam upacara chanoyu berikutnya. Walaupun jaku adalah tujuan akhir dari upacara chanoyu bukan berarti bahwa jaku yang paling penting. Tanpa wa, kei, sei, jaku tidak bisa muncul. Oleh karena itu, keempat prinsip ( $w a, k e i$, sei, jaku) sangat penting dan tidak dapat terpisahkan satu sama lain.

\section{Referensi}

Jary, David., Jary, Julia. (1991). Collins Dictionary of Sociology. Collins.

Kastuti, TI. (2018). Nilai Filosofis dalam Chanoyu. Japanese Research on Linguistics, Literature, and Culture 1 (1), 79-91. http://dx.doi.org/10.33633/jr.v1i1.2129.

Mittwer, Henry. (1992). The Art of Chabana: Flowers for the Tea Ceremony. Vermont \& Tokyo: Charles E. Tuttle Company, Inc.

Noviana, F. (2015). Kesederhanaan Wabicha dalam Upacara Minum The Jepang. Izumi 2 (2), 34-43.

Sadler, A.L., McCabe, Shaun., Sato, Kolwasaki. (2011). The Japanese Tea Ceremony: Cha No $Y u$. Tuttle Publishing.

Sen, XVShoshitsu. (1993). Chanoyu Handbook One. Kyoto: Urasenke Foundation. 
Sen, XVShoshitsu. (1979). Tea Life, Tea Mind. Weatherhill.

Suzuki, DT. (1964). Zen And Japanese Culture. New York: Princeton University Press.

Suzuki, DT. (1964). An Introduction to Zen Buddhism. New York: Grove Press, Inc.

Taylor, Edward B. (1871). Primitive Culture. London.

Yamamura, Kozo. (2006). The Cambridge History of Japan Volume 3. New York: Cambridge University Press.

ハルメート.シング. (日付不明). 茶道という文化. 4-10.

Japanese Tea Ceremony: http://en.wikipedia.org/wiki/Japanese_tea_ceremony (diakses pada 20 Desember 2014)

抹茶に親しむ会： http://seesaawiki.jp/w/tea8/d/\%CB\%F5\%C3\%E3\%A4\%CB\%BF\% C6\%A4\%B7\%A4\%E0\%B2\%F1 (diakses pada 16 Januari 2015).

「薄茶·鏡面点」: http://blog.goo.ne.jp/ikitugian/c/00fa4c43b1df6f55a1e63c5a4ef05 882 (diakses pada 16 Januari 2015)

もう一つ習い事を増やそう: http://blogs.yahoo.co.jp/mwbhappygolucky/ 31712355.html (diakses pada 16 Januari 2015)

帛紗の扱い: http://verdure.tyanoyu.net/temae0101.html\#03 (diakses pada 16 Januari 2015)

表千家と裏千家の違い: http://tokitama.s7.xrea.com/others/sado-chigai.html (diakses pada 16 Januari 2015)

Zen: http://id.wikipedia.org/wiki/Zen (diakses pada 1 Febuari 2015)

Ichi-go_ichi-e. http://en.wikipedia.org/wiki/Ichi-go_ichi-e (diakses pada 2 Febuari 2015)

Angelita, Nove. Analisis Unsur Buddha Zen Dalam Arsitektur Chashitsu: eprints.binus.ac.id/4301/ (diakses pada 5 Febuari 2015)

Anastasia, MCWP. (2010). Prinsip Dasar Buddha Zen Dalam Chanoyu: eprints.binus.ac.id/13237/ (diakses pada 5 Febuari 2015)

Asakichi. Japanese Tea Ceremony. Wa Kei Sei Jaku:

http://www.chanoyu.com/WaKeiSeiJaku.html (diakses pada 20 Desember 2014)

The Japanese Tea Ceremony. (2007). Japanese tea ceremony Utensils: http://japanese- teaceremony.net/utensils.html (diakses pada 16 Januari 2015)

Wikipedia. Jepang: http://id.wikipedia.org/wiki/Jepang (diakses pada 2 Febuari 2015) 